Check for updates

Cite this: RSC Adv., 2018, 8, 7134

\title{
Antioxidant and anti-inflammatory effects of polyphenols extracted from Ilex latifolia Thunb
}

\author{
Tian-Tian Zhang, (D) $\uparrow^{\mathrm{ab}}$ Ting Hu, $\uparrow^{\mathrm{c}}$ Jian-Guo Jiang, (D)*a Jing-Wen Zhao ${ }^{d}$ \\ and Wei Zhu*d
}

To promote the rational and effective application of llex latifolia Thunb., a Chinese bitter tea widely consumed as a health beverage, polyphenols were extracted from its leaves and their cellular antioxidant activity (CAA) and anti-inflammatory effect against mouse macrophage RAW 264.7 cells were analyzed. Results showed that the antioxidant capacity of polyphenols was high, and their CAA values in PBS wash and no PBS wash protocols were $6871.42 \pm 85.56$ and $25161.61 \pm 583.55 \mu \mathrm{mol}$ QE (quercetin equivalents)/100 g phenolic extracts, respectively. In addition, polyphenols from I. latifolia displayed strong inhibition on LPS-induced NO-production in RAW 264.7 cells. Polyphenol treatment inhibited the release of pro-inflammatory cytokines (TNF- $\alpha, \mathrm{IL}-1 \beta$ and IL-6) induced by LPS in a dose-dependent manner by ELISA and mRNA expression analysis. Western blot results showed that the anti-inflammatory activity of polyphenols from I. latifolia might be exerted through inhibiting the activation of MAPKs (ERK and $\mathrm{JNK}$ ) and NF-KB to decrease NO, COX-2 and pro-inflammatory cytokines production. Thus, the polyphenol enriched extracts from I. latifolia are a good source of natural antioxidants with a beneficial effect against inflammation, and they may be applied as a food supplement and/or functional ingredient.

Received 22nd December 2017 Accepted 5th February 2018

DOI: 10.1039/c7ra13569f

rsc.li/rsc-advances antioxidants have been considered as endocrine disrupters or even carcinogenic agents, and interest in developing natural nutritional antioxidants has been increasing due to their welldocumented impact on human health. ${ }^{6-8}$ Dietary supplements are becoming attractive alternatives as disease-preventive agents. Among the secondary metabolites of various plant species, polyphenols have been extensively studied because of their antioxidant, anti-cancer, anti-inflammatory and antihyperglycemic effects in humans. ${ }^{9}$

Ilex latifolia Thunb., a kind of herbal tea, is called ku-dingcha in Chinese and is widely consumed in China and other Southeast Asia countries including Singapore, Malaysia and Vietnam. ${ }^{10}$ I. latifolia has become more popular in the last few years due to its public acceptance as a functional tea beverage with highly advantageous nutrition and many beneficial functions, such as antioxidant, anti-obesity, anti-diabetic, hepatoprotective, neuroprotective effects and so on. ${ }^{\mathbf{1 1 , 1 2}}$ Recently, more studies have been devoted to the extraction and identification of main chemicals in I. latifolia such as flavonoids, saponins, polysaccharides and alkaloids and their potential health benefits in antioxidant, anti-obesity, neuroprotective, antidiabetic, hepatoprotective and anticomplementary effects. ${ }^{\mathbf{1 1 - 1 3}}$ However, little attention has been paid to the extraction and bioactivities of polyphenols of I. latifolia. Therefore, searching for alternative natural active ingredients such as polyphenols in $I$. latifolia is necessary for its application on food additives and health products. 
On the basis of these reports, polyphenols obtained from $I$. latifolia were evaluated antioxidant, and anti-inflammatory activities. The aim of this work was to (i) measure the total phenolic content; (ii) determine the cellular antioxidant capacity; (iii) determine the anti-inflammatory activity on NO production in LPS-stimulated macrophage RAW 264.7 cells; (iv) demonstrate possible targeted pathway.

\section{Materials and methods}

\section{Plant materials}

I. latifolia cultivated in Hainan Province, China, was purchased from Forest Drugstore Chain Co. (Guangzhou, China) and were authenticated by South China Botanical Garden, Chinese Academy of Sciences, where voucher specimens were kept. Samples were air-dried under shade for one week and ground in a cutting mill to pass through a 50-mesh sieve to obtain fine powder. The dried materials were stored at room temperature in a desiccator until use.

\section{Reagents}

Dulbecco's modified eagle medium (DMEM), fetal bovine serum (FBS), Hank's balanced salt solution (HBSS) and penicillin/streptomycin were obtained from GIBCO (Grand Island, NY, USA). (3-4,5-Dimethylthiazol-2-yl)-2,5-diphenyl tetrazolium bromide (MTT), 2', $7^{\prime}$-dichlorofluorescin diacetate (DCFH-DA), fluorescein disodium salt, 2,2'-azobis(2amidinopropane)dihydrochloride (ABAP), Folin-Ciocalteu reagent, lipopolysaccharides (LPS), dexamethasone (DXM) and bicinchoninic acid (BCA) kit were purchased from Sigma Aldrich (St. Louis, MO, USA). TRIzol Reagent was purchased from Invitrogen (Carlsbad, CA, USA). The antibodies against phospho-ERK, phospho-JNK, NF-KB and GAPDH were obtained from Cell Signaling Technology (Beverly, MA, USA). The water used in all assays was ultrapure by a Milli-Q water purification system from Millipore. All other reagents used in this study were of analytical grade.

\section{Extraction of polyphenols}

Ultrasound-assisted extraction was conducted following the method described by Izadiyan et al. (2016) with some modifications ${ }^{14}$ Briefly, ten grams of the dried powder were weighed and mixed with $200 \mathrm{~mL}$ of $50 \%(\mathrm{v} / \mathrm{v})$ aqueous ethanol. The mixture was subjected to the continuous ultrasonic treatment in a $60 \mathrm{~W}$ (ultrasonic power) ultrasonic bath for $100 \mathrm{~min}$ at $30{ }^{\circ} \mathrm{C}$. The samples were then centrifuged at $1500 \times g$ for $10 \mathrm{~min}$. The supernatant was recovered and then evaporated to near dryness under a vacuum at $40{ }^{\circ} \mathrm{C}$. The samples were collected and stored at $4{ }^{\circ} \mathrm{C}$ in a refrigerator for further analysis.

\section{Determination of total phenolic content and phenolic composition}

The total phenolic content (TPC) was determined using the Folin-Ciocalteu method with some modifications. ${ }^{15,16}$ Two hundred micro liters of phenolic extract was transferred to a $10 \mathrm{~mL}$ of volumetric flask and then mixed with $0.5 \mathrm{~mL}$ of undiluted Folin-Ciocalteu reagent. After $1 \mathrm{~min}, 1.5 \mathrm{~mL}$ of $20 \%$ (w/v) $\mathrm{Na}_{2} \mathrm{CO}_{3}$ was added and the volume was made up to $10 \mathrm{~mL}$ with water. The samples were incubated at $40{ }^{\circ} \mathrm{C}$ for $2 \mathrm{~h}$. The absorbance of the sample and standard were measured at $760 \mathrm{~nm}$, using a UV-Vis spectrophotometer. The total polyphenolic content was calculated on the basis of the standard curve for gallic acid and expressed as $\mathrm{mg}$ of gallic acid equivalents (GAE) per g dry material plant (mg GAE/g plant material). The calibration curves (five data points) were linear with $R^{2}=$ 0.999 .

The phenolic composition was determined by the LC-MS (liquid chromatography-mass spectrometry) analysis according to our published article. ${ }^{17}$

\section{Cell culture}

Human hepato cellular carcinoma HepG-2 cell lines and RAW 264.7 murine macrophages from the cell bank of the Chinese Academy of Sciences (CAS, Shanghai, China) were cultured in plastic dishes containing DMEM supplemented with $10 \%$ FBS, penicillin/streptomycin in a $5 \% \mathrm{CO}_{2}$ humidified atmosphere at $37{ }^{\circ} \mathrm{C}$.

\section{Cytotoxicity}

The cell viability was measured using MTT assay. ${ }^{18-21}$ Briefly, exponential growth phase HepG-2 cells and RAW 264.7 cells were seeded at a density of $6 \times 10^{3}$ cells per well in 96-well culture plates and treated with the various concentrations of polyphenols for $24 \mathrm{~h}$. After incubation, the media solution was removed, and the cells were washed twice with phosphatebuffered saline (PBS). One hundred micro liters of media containing $0.1 \%$ MTT $\left(0.5 \mathrm{mg} \mathrm{mL}^{-1}\right)$ was added to each well and the cells were incubated for additional $4 \mathrm{~h}$ at $37{ }^{\circ} \mathrm{C}$. Then the medium in each well were removed and replaced with $150 \mu \mathrm{L}$ of dimethyl sulfoxide to dissolve the formazan crystals. The optical density was measured using an ELISA plate reader at $570 \mathrm{~nm}$. Control cells were cultured with fresh medium only. The optical density of formazan generated by control cells was taken as $100 \%$ survival. Cell viability $(\%)=$ polyphenols $\left(\mathrm{OD}_{570}\right) /$ control $\left(\mathrm{OD}_{570}\right) \times 100 \%$.

\section{Cellular antioxidant activity (CAA)}

The CAA of phenolic extracts was determined using the method of Wolfe \& Liu (2007). ${ }^{22}$ Briefly, exponential growth phase HepG2 cells with a density of $6 \times 10^{4}$ cells per $\mathrm{mL}$ were seeded in 96well culture plates $(100 \mu \mathrm{L}$ per well) and incubated for $24 \mathrm{~h}$. After incubation, the media solution was removed, and the cells were washed twice with PBS. Micro plates were treated in triplicate for $1 \mathrm{~h}$ with $100 \mu \mathrm{L}$ of medium containing phenolic extracts plus $50 \mu \mathrm{M}$ DCFH-DA. Certain wells were washed with $100 \mu \mathrm{L}$ of PBS (PBS wash protocol) and certain wells were not washed (no PBS wash protocol). Then $600 \mu \mathrm{M}$ ABAP in $100 \mu \mathrm{L}$ of Hanks' Balanced Salt Solution (HBSS) was added to the cells, and the 96-well micro plate was placed in a Fluoroskan Ascent fluorescent plate reader (Soft Max systems, Molecular Devices, US) at $37{ }^{\circ} \mathrm{C}$. Emission at $538 \mathrm{~nm}$ was measured after excitation at $485 \mathrm{~nm}$ every $5 \mathrm{~min}$ for $1 \mathrm{~h}$. PBS wash protocol means that cells 
are pretreated with polyphenols before ABAP was added, and no PBS wash means that cells are co-treated with polyphenols and ABAP. Each plate included triplicate control and blank wells. Control wells contained cells treated with DCFH-DA and ABAP. Blank wells contained cells treated with DCFH-DA and HBSS. After the subtraction of the blank and the initial fluorescence values, the area under the fluorescence versus time curve was calculated to determine the CAA value at various concentrations of polyphenols using the following equation: ${ }^{23}$

$$
\mathrm{CAA}(\text { units })=1-\left(\int \mathrm{SA} / \int \mathrm{CA}\right)
$$

where $\int \mathrm{SA}$ and $\int \mathrm{CA}$ are the integrated area under the fluorescence versus time curve of the sample and control, respectively.

The $\mathrm{EC}_{50}$ (median effective dose) of the polyphenols was calculated from the median effect plot of $\log \left(f_{\mathrm{a}} / f_{\mathrm{u}}\right)$ versus $\log$ (dose), where $f_{\mathrm{a}}$ is the fraction affected by the treatment (CAA unit) and $f_{\mathrm{u}}$ is the fraction unaffected by the treatment (1 - CAA unit). Results were expressed as $\mu$ mol quercetin equivalents (QE) per $100 \mathrm{~g}$ of phenolic extracts.

\section{Nitric oxide assay}

Nitric oxide assay was determined using the Griess reagent system. $^{20,24}$ RAW 264.7 cells were seeded at a density of $2.5 \times 10^{5}$ cells per well in 24-well plates and then incubated with or without LPS in the absence or presence of various concentrations of polyphenols for $24 \mathrm{~h}$. The final concentration of LPS was $1 \mu \mathrm{g} \mathrm{mL}{ }^{-1}$. After LPS-stimulation for $24 \mathrm{~h}$, cell culture medium was collected to measure the amount of NO using Griess reagent, which was made by mixing equal volumes of $1 \%$ sulphanilamide in 5\% phosphoric acid and $0.1 \% N$-1-naphtylethylenediamine dihydrochloride in distilled water. In brief, one hundred microlitres of Griess reagent were added to an equal volume of cell culture medium in a 96-well plate and incubated for $10 \mathrm{~min}$ at room temperature, and then the absorbance was measured on a microplate reader at $540 \mathrm{~nm}$ using serial dilutions of sodium nitrite as a standard. ${ }^{25,26}$ Fresh culture medium was used as the blank in all experiments and dexamethasone was used as a positive drug in this assay. NO inhibition rate $=\left[\operatorname{LPS}\left(\mathrm{OD}_{540}\right)-\right.$ sample $\left.\left(\mathrm{OD}_{540}\right)\right] /\left[\mathrm{LPS}\left(\mathrm{OD}_{540}\right)-\right.$ blank $\left.\left(\mathrm{OD}_{540}\right)\right] \times 100 \%$.

\section{Enzyme-linked immunosorbent assay (ELISA)}

Tumour necrosis factor- $\alpha$ (TNF- $\alpha$ ), interleukin-1 $\beta$ (IL-1 $\beta$ ) and IL6 levels in cell culture medium were determined by ELISA following the manufacturer's instructions. RAW 264.7 cells were seeded at $2.5 \times 10^{5}$ cells per well into 24 -well plates. Cells were treated with or without LPS $\left(1 \mu \mathrm{g} \mathrm{mL}^{-1}\right)$ in the absence or presence of various concentrations of phenolic extracts for $24 \mathrm{~h}$. After LPS-stimulation for $24 \mathrm{~h}$, the supernatant was collected to test the levels of TNF- $\alpha$, IL-1 $\beta$ and IL- 6 using ELISA kits specific for mouse ( $R \& D$ systems) according to the manufacturer's instructions.

\section{Quantitative real-time PCR analysis}

For the analysis of mRNA expression by quantitative real-time PCR, RAW 264.7 cells were harvested after incubation with or without LPS $\left(1 \mu \mathrm{g} \mathrm{mL} \mathrm{mL}^{-1}\right)$ in the absence or presence of different concentrations $\left(100,200,300 \mu \mathrm{g} \mathrm{mL}^{-1}\right)$ of polyphenols for $12 \mathrm{~h}$. Total cellular RNA from RAW 264.7 cells was isolated using TRIzol Reagent kit following the manufacturer's instructions. RNA was reversely transcribed into cDNA using an RT-PCR kit with an oligo-adaptor primer. Quantification of mRNA levels was performed by "IQ5 Real-Time PCR Detection System" using the Light Cycler instrument with the Fast Start DNA Master SYBR Green I kit. The nucleotide sequences of the primers used were as follows: TNF- $\alpha$ (forward, $5^{\prime}$-GGG GAT TAT GGC TCA GGG TC-3', reverse, $5^{\prime}$-CGA GGC TCC AGT GAA TTC GG-3'), iNOS (forward, $5^{\prime}$ CGG CAA ACA TGA CTT CAG GC- $3^{\prime}$, reverse, $5^{\prime}$-GCA CAT CAA AGC GGC CAT AG-3'), IL-1 $\beta$ (forward, $5^{\prime}$-CCA TGG AAT CCG TGT CTT CCT-3', reverse, 5'-GTC TTG GCC GAG GAC TAA GG-3'), IL-6 (forward, 5'-GTA CTC CAG AAG ACC AGA GG-3' ${ }^{\prime}$, reverse, $5^{\prime}$-TGC TGG TGA CAA CCA CGG CC-3'), COX-2 (forward, $5^{\prime}$-CAG CAA ATC CTT GCT GTT CC-3' , reverse, 5'-TGG GCA AAG AAT GCA AAC ATC- $3^{\prime}$ ) and GAPDH (forward, $5^{\prime}$-CAC TCA CGG CAA ATT CAA CGG CAC-3', reverse, 5'-GAC TCC ACG ACA TAC TCA GCA-3'). Each sample was tested three times and a mean value was used for the determination of messenger RNA levels. GAPDH was used to normalize gene expression levels for further analysis. Following the normalization, the group data were calculated by formula $2^{-\Delta \Delta \mathrm{Ct}}$ and expressed as mean (SD) and differences in transcript levels between groups were analyzed by SPSS $17.0 .^{27,28}$

\section{Western blotting}

The culture medium was discarded and the remaining cells were harvested at the indicated conditions for western blot analysis as described previously. ${ }^{29,30}$ The cells were washed twice by ice-cold PBS and lysed with RIPA cell lysis buffer (50 mM Tris-HCl (pH 7.4), $150 \mathrm{mM} \mathrm{NaCl}, 1 \%$ Nonidet P-40, and $0.1 \%$ sodium dodecyl sulphate, SDS) supplemented with $5 \mu \mathrm{g} \mathrm{mL}$ each of leupeptin and aprotinin for $30 \mathrm{~min}$ at $4{ }^{\circ} \mathrm{C}$. The cell debris was removed by micro-centrifugation and the protein concentration was determined using a BCA protein assay kit according to the manufacturer's instruction. Equal amount of cellular protein were separated by $12 \%$ sodium dodecyl sulfatepolyacryl amide gel electrophoresis (SDS-PAGE) and then transferred to polyvinylidene difluoride (PVDF) membranes, which were activated in methanol. The membranes were blocked using 5\% skim milk for $1 \mathrm{~h}$ at room temperature and sequentially incubated overnight at $4{ }^{\circ} \mathrm{C}$ in primary antibodies against phospho-ERK, phospho-JNK, NF- $\mathrm{B}$ and GAPDH. After washing with Tween 20/Tris-buffered saline (TTBS), the membranes were incubated with horseradish-peroxidaseconjugated secondary antibody for $2 \mathrm{~h}$ at room temperature, and then followed by ECL detection. GAPDH was used to normalize for protein loading and the intensity of the bands was determined using densitometric analysis.

\section{Statistical analysis}

The results were expressed as mean values \pm standard deviations of the three independent experiments. Statistical significance of differences between the mean values were calculated using one-way analysis of variance (ANOVA) followed by the 
Tukey post hoc test $(P<0.05)$. All analyses were carried out using SPSS 11.5 software.

\section{Results and discussion}

\section{The contents of polyphenols and phenolic composition}

The content of total polyphenols was $187.86 \mathrm{mg}$ GAE/g plant material using the Folin-Ciocalteu method. In addition, LC-MS analysis of polyphenols from I. latifolia revealed the presence of (1) quinic acid, (2) 3-caffeoylquinic acid, (3) 5-caffeoylquinic acid, (4) shikimic acid, (5) 4-caffeoylquinic acid, (6) rutin, (7) hyperoside, (8) 3,4-di-caffeoylquinic acid, (9) 3,5-dicaffeoylquinic acid and (10) 4,5-di-caffeoylquinic acid as shown in our previous published paper. ${ }^{17}$

\section{Cellular antioxidant activity}

The cellular antioxidant activity of polyphenols from I. latifolia was measured using CAA assay. CAA assay is more physiologically relevant to biological systems and reflects the absorption, metabolism, and distribution of antioxidants at the cellular level. ${ }^{31}$ Initially, the cell viability experiment of HepG-2 cells was performed at 100-300 $\mu \mathrm{g} \mathrm{mL} \mathrm{mL}^{-1}$ concentration and there was no significant cytotoxicity (cell viability $\geq 96 \%$ ) of polyphenols at the concentration up to $300 \mu \mathrm{g} \mathrm{mL} \mathrm{m}^{-1}$ (shown in Table 1). In this assay, PBS wash and no PBS wash protocols were both used to manage the cells after one hour of incubation. The $\mathrm{EC}_{50}$ and CAA values of polyphenols from I. latifolia in PBS wash and no PBS wash protocols are presented in Table 2. In the PBS wash protocol, $\mathrm{EC}_{50}$ and CAA values of polyphenols were $251.94 \pm 6.18$ $\mu \mathrm{g} \mathrm{mL}{ }^{-1}$ and $6871.42 \pm 85.56 \mu \mathrm{mol}$ QE/100 g phenolic extracts, respectively. Those compounds that are only loosely associated with the cell membrane can be removed by PBS wash protocols. ${ }^{32}$ In the no PBS wash protocol, $\mathrm{EC}_{50}$ and CAA values of polyphenols were $28.85 \pm 0.68 \mu \mathrm{g} \mathrm{mL} \mathrm{mL}^{-1}$ and $25161.61 \pm 583.55 \mu \mathrm{mol} \mathrm{QE} / 100 \mathrm{~g}$ phenolic extracts, respectively. $\mathrm{EC}_{50}$ is calculated from the linear regression of the median effect curve, and then converted into CAA values. The CAA and $\mathrm{EC}_{50}$ values are negatively correlated, and the lower level of $\mathrm{EC}_{50}$ means higher CAA activity.

\section{Effect of polyphenols on LPS-induced NO production in macrophages}

Macrophages are the important immune cells in mammals and produce great amount of NO after stimulated by LPS, which

Table 1 The MTT assay was used for measurement of viability of HepG-2 and RAW 264.7 cells exposed to polyphenols from I. latifolia

\begin{tabular}{lcc}
\hline \multirow{2}{*}{$\begin{array}{l}\text { Concentration } \\
\left(\mu \mathrm{g} \mathrm{mL} \mathrm{mL}^{-1}\right)\end{array}$} & Cell viability $^{a}(\%)$ & \\
\cline { 2 - 3 } 100 & HepG-2 cells & RAW 264.7 cells \\
200 & $100.42 \pm 1.98$ & $100.10 \pm 2.45$ \\
300 & $99.69 \pm 2.15$ & $98.11 \pm 3.29$ \\
& $96.28 \pm 2.68$ & $97.39 \pm 2.56$
\end{tabular}

${ }^{a}$ All data were expressed as relative cell viability (\%) compared with untreated group which cell viability was considered as $100 \%$. Values are expressed as mean $\pm \mathrm{SD}(n=6)$.
Table $2 \mathrm{EC}_{50}$ and CAA values (mean $\pm \mathrm{SD}, n=3$ ) of polyphenols from I. latifolia by HepG2 cell model

\begin{tabular}{lcc}
\hline & $\mathrm{EC}_{50}\left(\mu \mathrm{g} \mathrm{mL}{ }^{-1}\right)$ & $\begin{array}{l}\mathrm{CAA}(\mu \mathrm{mol} \mathrm{QE} / 100 \mathrm{~g} \\
\text { phenolic extracts })\end{array}$ \\
\hline PBS wash & $251.94 \pm 6.18$ & $6871.42 \pm 85.56$ \\
No PBS wash & $28.85 \pm 0.68$ & $25161.61 \pm 583.55$ \\
\end{tabular}

results in inflammation. ${ }^{33,34}$ To further study the activity of polyphenols against inflammation, treatment of LPS-induced RAW 264.7 macrophages with polyphenols was performed to determine its dosage-effect against NO production. Initially, the effect of polyphenols on the cell viability of RAW 264.7 cells was measured by a MTT assay and the data were shown as relative cell viability referred to control (equal to 100\%). Results showed that polyphenols did not cause toxicity to the cells (cell viability $\geq 97 \%$ ), implementing that the NO suppressive action of polyphenols at the highest concentration was not due to the cytotoxicity effect (Table 1 ).

To determine whether polyphenols from I. latifolia can regulate inflammatory mediators in LPS-induced RAW 264.7 macrophages, NO production was determined in the culture medium using Griess reagent. The results (Fig. 1) were reported as NO inhibition rate means \pm standard error measured from at least three independent experiments. Fig. 1 shows a concentration-dependent NO release inhibition rates of polyphenols, where NO release inhibition rates of polyphenols were $66.53 \pm$ $0.87,21.17 \pm 1.42,2.71 \pm 0.29 \%$, corresponding to the concentration of 300,200 and $100 \mu \mathrm{g} \mathrm{mL}^{-1}$. Interestingly, NO release inhibition rate of polyphenols at the concentration of $300 \mu \mathrm{g} \mathrm{mL}^{-1}$ was found to exceed that of dexamethasone at the concentration of $50 \mu \mathrm{g} \mathrm{mL}{ }^{-1}$, where the NO release inhibition

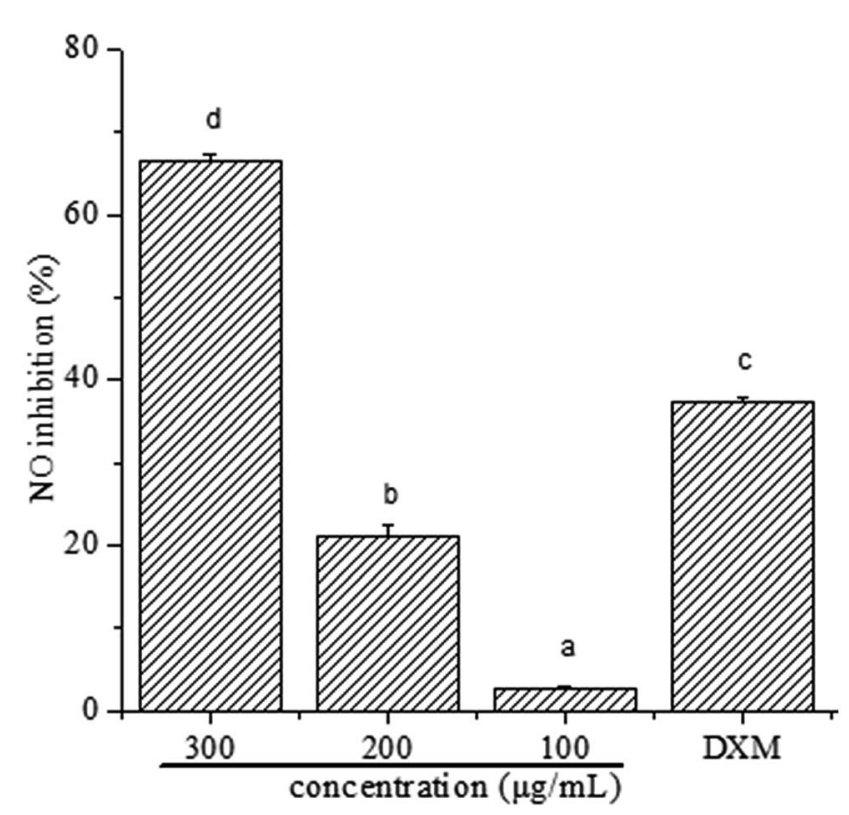

Fig. 1 Effect of polyphenols on NO production in RAW 264.7 cells. The values represent the means \pm SD from three independent experiments. Different letters represent significant differences $(P<0.05)$. 
rate is $37.30 \pm 0.52 \%$. Many previous literatures showed that phenolic extracts had good anti-inflammatory activity. After the treatment of polyphenols from Hibiscus sabdariffa leaves, the reduction of LPS-induced NO production dose-dependently in RAW 264.7 cells indicates the phenolic extracts' potential antiinflammatory activity. ${ }^{35}$ Polyphenols extracted from chokeberry (Aronia melanocarpa (Michx.) Elliot) exhibited antiinflammatory activity. ${ }^{1}$ Thus, it is possible to demonstrate that polyphenols from I. latifolia may be a promising candidate for anti-inflammation treatment. Previous research has reported that polyphenols from I. latifolia possesses antiinflammatory activity, however there are few literature reports on its anti-inflammatory mechanism. ${ }^{12}$

Effects of polyphenols on pro-inflammatory cytokines (TNF- $\alpha$, IL-1 $\beta$, IL-6) production by ELISA

Macrophages play an important role in both the specific and non-specific immune responses, and they are a major source of various cytokines involved in inflammation, hematopoiesis and other homeostatic processes. ${ }^{36}$ Activation by inflammatory stimuli could produce many inflammatory mediators including NO and pro-inflammatory cytokines such as TNF- $\alpha$, IL-1 $\beta$ and IL-6. ${ }^{37}$ However, if out of control, the inflammatory mediators could be involved in the pathogenesis of many inflammatory disorders. Therefore, the inhibition of the release of these inflammatory mediators is a crucial target in the treatment of inflammatory diseases.

In order to test the possibility that polyphenols from I. latifolia might modulate the inflammatory response, the proinflammatory cytokines (TNF- $\alpha$, IL-1 $\beta$, IL-6) were evaluated by ELISA. The concentration of dexamethasone (DXM) was $50 \mu \mathrm{g} \mathrm{mL} \mathrm{m}^{-1}$. To reach detectable ranges of released proinflammatory cytokines in cultured media, LPS treatment was extended up to $24 \mathrm{~h}$. After stimulation by LPS for $24 \mathrm{~h}$, the production of TNF- $\alpha$ (Fig. 2A), IL-1 $\beta$ (Fig. 2B), IL-6 (Fig. 2C) was markedly increased. Polyphenols treatment (at the concentration of $300,200,100 \mu \mathrm{g} \mathrm{mL} \mathrm{mL}^{-1}$ ) inhibited the release of proinflammatory cytokines induced by LPS in a dose-dependent manner (Fig. 2). Especially, the IL-1 $\beta$ level after treatment with the polyphenols at the concentration of $300 \mu \mathrm{g} \mathrm{mL}{ }^{-1}$ was $394.01 \pm 22.17 \mathrm{pg} \mathrm{mL}^{-1}$, which was very close to that of dexamethasone at the concentration of $50 \mu \mathrm{g} \mathrm{mL} \mathrm{m}^{-1}$ (Fig. 2B). Previous studies have demonstrated that polyphenols possess anti-inflammatory activity due to the suppression of the release of pro-inflammatory mediators. ${ }^{38}$ The above results suggested that polyphenols from I. latifolia suppressed the initial phase of the LPS-induced inflammatory response.

\section{Effect of polyphenols on the involved mRNA expression}

Nitric oxide production is a characteristic feature of activated macrophages. In macrophages, NO is primarily released by inducible nitric oxide synthase (iNOS), which is the enzyme produced by external stimulation, and high levels of this free radical could cause damage to a target tissue during an infection. ${ }^{39,40}$ Prostaglandin E2 (PGE2), an inflammatory mediator, exerts a crucial role during inflammation. The synthesis of
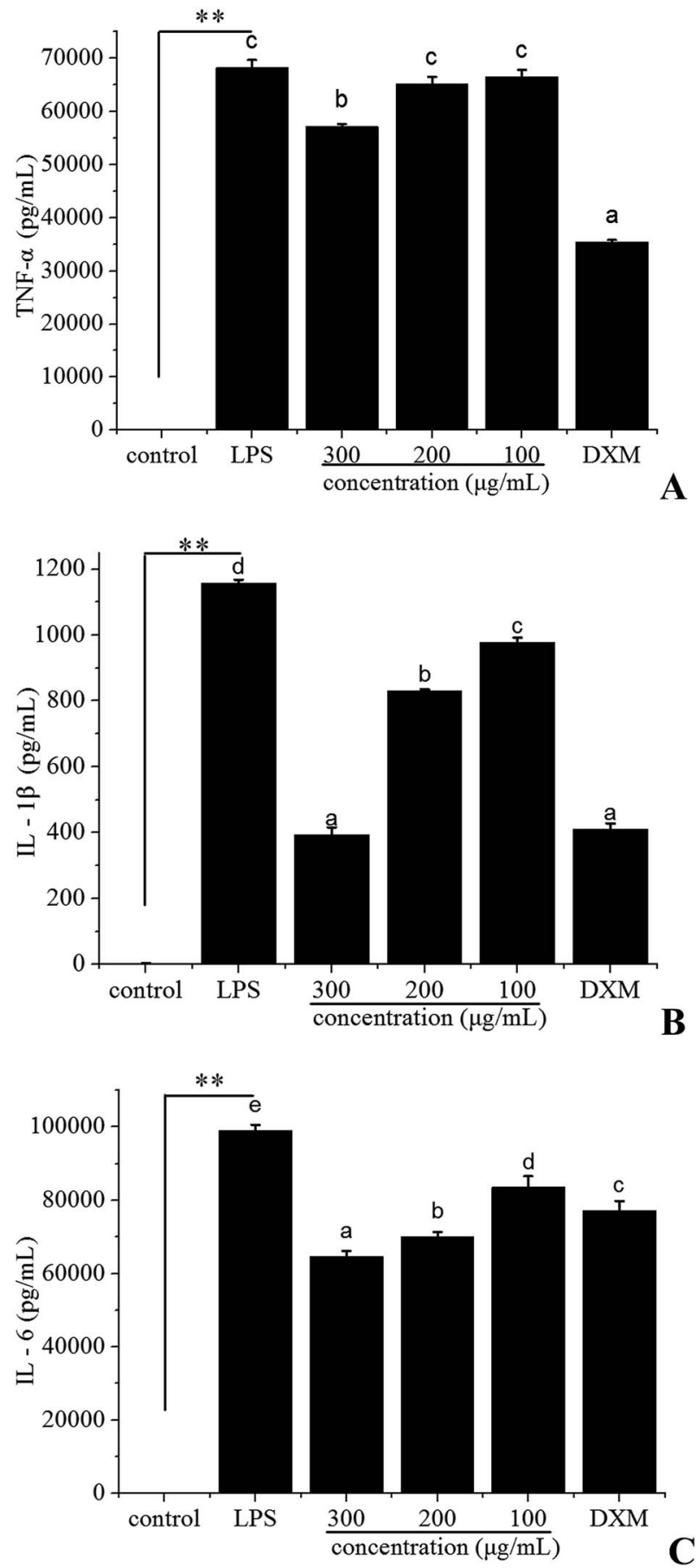

Fig. 2 Effect of polyphenols from I. latifolia on LPS-induced TNF- $\alpha$ (A), IL-1 $\beta$ (B) and IL-6 (C) levels in RAW 264.7 macrophages by ELISA. Data represent the means $\pm \mathrm{SD}$ from three separate experiments. $* * P<0.01$ as compared with the control group. Different letters represent significant differences $(P<0.05)$

PGE2 is dependent on cyclooxygenase-2 (COX-2), which is a prostaglandin-endoperoxide synthase enzyme. ${ }^{35}$ It is involved in inflammatory diseases.

Because iNOS and COX-2 are the crucial enzymes for the production of NO and PGE2, respectively, we examined the mRNA expression level of iNOS and COX-2 in LPS-stimulated 
RAW 264.7 cells using quantitative real-time PCR to investigate the anti-inflammatory effect of polyphenols from I. latifolia. When RAW 264.7 cells were treated with LPS for $12 \mathrm{~h}$, the iNOS (Fig. 3A) and COX-2 (Fig. 3B) mRNA expression were markedly increased; however, the mRNA expression of iNOS and COX-2 were significantly suppressed in a dose-dependent manner in LPS-stimulated RAW 264.7 cells treated with polyphenols from I. latifolia at a concentration of 300,200 and $100 \mu \mathrm{g} \mathrm{mL} \mathrm{m}^{-1}$. Interestingly, Fig. 3A showed that polyphenols significantly inhibited the mRNA expression of iNOS at the concentration of $300 \mu \mathrm{g} \mathrm{mL}{ }^{-1}$, which was very close to that of dexamethasone at the concentration of $50 \mu \mathrm{g} \mathrm{mL} \mathrm{m}^{-1}$, supporting that polyphenols from $I$. latifolia suppressed NO production by decreasing iNOS expression. Additionally, when RAW 264.7 cells were treated with polyphenols from $I$. latifolia at a concentration of $300 \mu \mathrm{g}$ $\mathrm{mL}^{-1}$, COX-2 production was decreased by about $70 \%$. Moreover, the effects of polyphenols from I. latifolia on the mRNA expression of pro-inflammatory cytokines including TNF$\alpha$ (Fig. 3C), IL-1 $\beta$ (Fig. 3D), IL-6 (Fig. 3E) were further investigated. The mRNA expression of pro-inflammatory cytokines was up-regulated after LPS stimulation and was significantly down-regulated by polyphenols treatment in a concentration dependent manner. These results were consistent with the above outcomes obtained by ELISA. It was confirmed that polyphenols from I. latifolia exhibited strong anti-inflammatory effect.

Effects of polyphenols on the MAPKs pathway and NF- $\kappa$ B signal pathway in LPS-stimulated RAW 264.7 macrophages

MAPKs play an important role in the signal transduction pathways that appear to be critical in inflammatory processes. ${ }^{20}$ JNK signaling regulates the expression of iNOS, whereas ERK signaling up-regulate iNOS expression and the production of pro-inflammatory cytokines including TNF- $\alpha$ and IL-6 in LPSstimulated macrophages. ${ }^{41}$ Therefore, the effect of polyphenols from I. latifolia on the LPS-induced MAPK phosphorylation was determined to investigate whether the MAPK
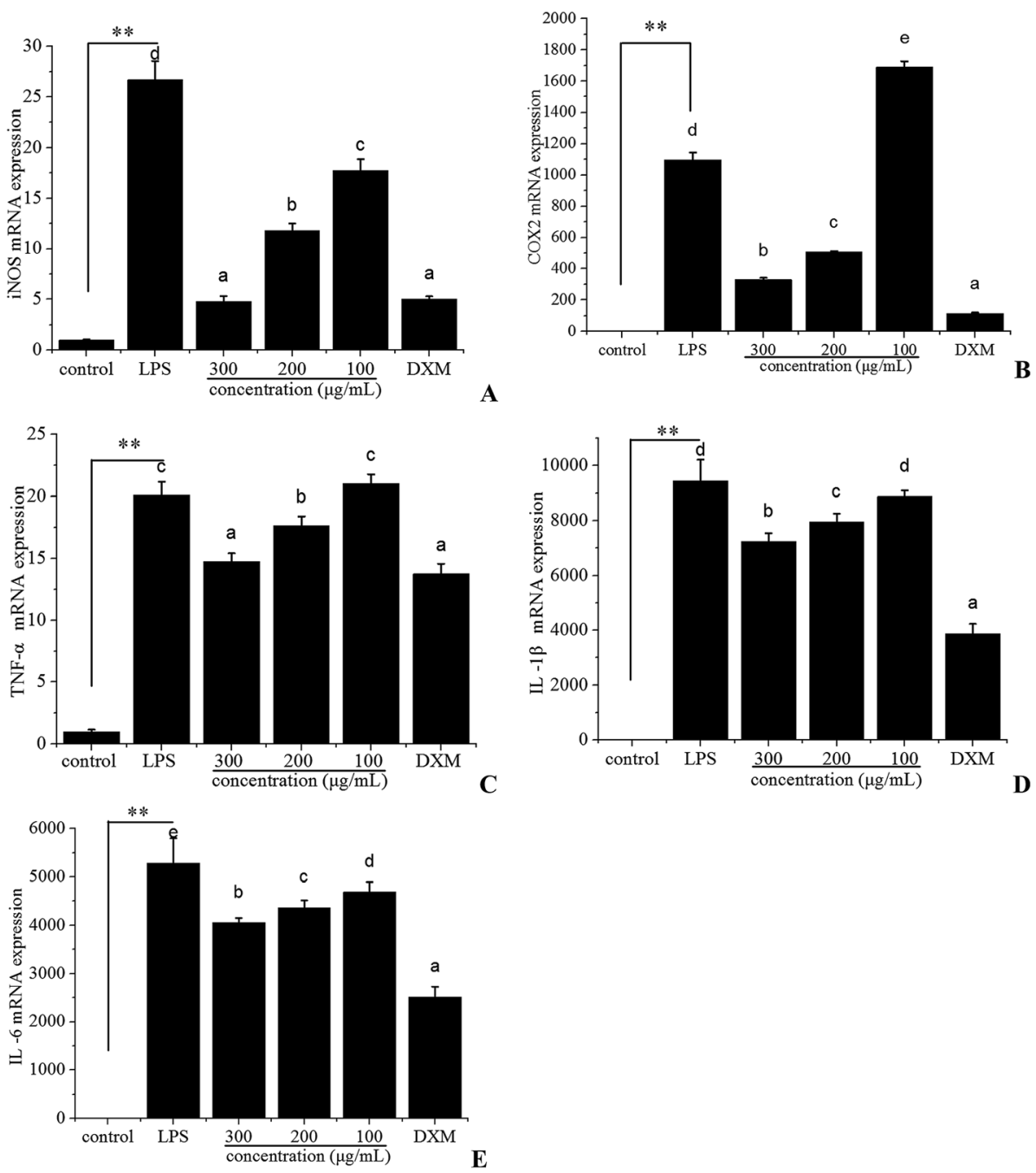

Fig. 3 Inhibitory effects of polyphenols on LPS-induced mRNA expression of iNOS (A), COX-2 (B), TNF- $\alpha$ (C), IL-1B (D), and IL-6 (E) in RAW 264.7 macrophages. Concentrations of pro-inflammatory cytokines were monitored as described in the methods section. Data represent the means \pm SD from three separate experiments. ${ }^{*} P<0.01$ as compared with the control group. Different letters represent significant differences $(P<0.05)$. 
pathways are involved in the inhibition of inflammatory mediators by polyphenols. As shown in Fig. 4A and B, LPS treatment for $1 \mathrm{~h}$ significantly induced the phosphorylation of ERK and JNK compared to un-stimulated cells. Three hours of pretreatment with polyphenols from I. latifolia $\left(100-300 \mu \mathrm{g} \mathrm{mL}^{-1}\right)$ significantly suppressed the LPS-induced phosphorylation of ERK and JNK in a concentration dependent manner. The experimental results are in accordance with published reports. Our previous report has shown that phosphorylation of MAPKs (ERK and JNK) was significantly inhibited by flavonoid glycosides from Rubus chingii Hu fruits in LPS-stimulated RAW 264.7 macrophages. ${ }^{20}$ These data indicate that the inhibition of inflammatory mediators by polyphenols from I. latifolia occurs probably through the inhibitions of the ERK and JNK activation.

As NF- $\kappa \mathrm{B}$ regulates the gene expression of pro-inflammatory cytokines and COX-2, it is a good target for treating inflammatory diseases. Moreover, many anti-inflammatory ingredients exert their effects by suppressing the NF- $\kappa \mathrm{B}$ signaling pathway. ${ }^{\mathbf{4 1}}$ Therefore, the effect of polyphenols $\left(100-300 \mu \mathrm{g} \mathrm{mL}{ }^{-1}\right)$ on the NF- $\kappa \mathrm{B}$ pathway activated by LPS in the macrophage cell line RAW 264.7 was investigated. RAW 264.7 cells were preincubated for $3 \mathrm{~h}$ with the polyphenols from I. latifolia and then stimulated with LPS $\left(1 \mu \mathrm{g} \mathrm{mL} \mathrm{m}^{-1}\right)$ for another $1 \mathrm{~h}$. Although LPS treatment markedly promoted NF- $\mathrm{B}$ activation in RAW 264.7 macrophages, the activation of NF- $\mathrm{B}$ was inhibited by polyphenols treatment in a dose-dependent manner (Fig. 4C). These data suggested that polyphenols from I. latifolia might decrease NO, COX-2 and pro-inflammatory cytokines production via inhibitions of MAPKs and NF- $\kappa \mathrm{B}$ activation. Interestingly, our previous study also showed that the polyphenols from I. latifolia exerted anti-atherosclerotic activity through

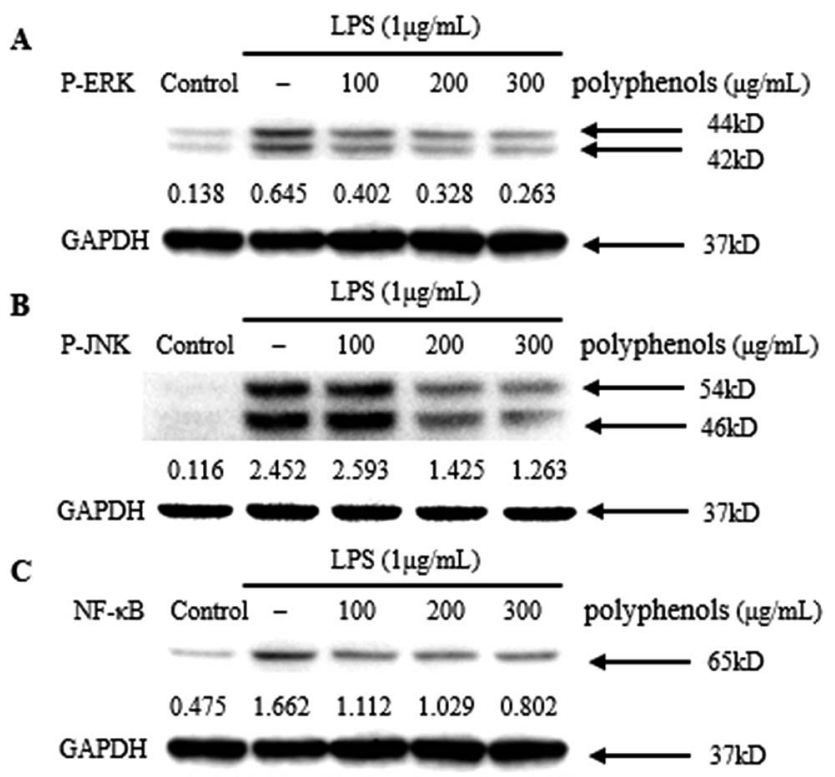

Fig. 4 Inhibitory effects of polyphenols on phosphorylation of MAPKs [ERK1/2 (A) and JNK (B)] and NF-KB in LPS-induced RAW 264.7 cells. Cells were treated with indicated concentrations of polyphenols for $3 \mathrm{~h}$, followed by induction with $1 \mu \mathrm{g} \mathrm{mL}^{-1}$ LPS for $1 \mathrm{~h}$. The blots shown are representative of three blots yielding similar results. suppressing NF- $\kappa$ B activation and phosphorylation of ERK1/2 in oxidized low-density lipoprotein (ox-LDL)-induced macrophages, indicating the specific role of the I. lactifolia polyphenols in the regulation of these two pathways.

\section{Conclusion}

In conclusion, polyphenols from I. latifolia have high antioxidant and anti-inflammatory activities. The CAA values of polyphenols in PBS wash and no PBS wash protocols were 6871.42 \pm 85.56 and $25161.61 \pm 583.55 \mu \mathrm{mol} \mathrm{QE} / 100 \mathrm{~g}$ phenolic extracts, respectively. Moreover, the polyphenols from I. latifolia showed strong inhibition on LPS-induced NO-production in RAW 264.7 cells. The polyphenols could decrease the production of NO, COX-2 and pro-inflammatory cytokines via inhibitions of MAPKs (ERK and JNK) and NF- $\mathrm{B}$ activation. Thus, the polyphenols enriched extracts from I. latifolia are good source of natural antioxidants with a beneficial effect against inflammation, and they may be applied as food supplement and/or functional ingredient. However, further research is needed to evaluate their anti-inflammatory activity in vivo.

\section{Conflicts of interest}

There are no conflicts to declare.

\section{Acknowledgements}

This project was supported by the National Natural Foundation of China (31301453), Scientific Research Projects of the State Administration of traditional Chinese medicine (JDZX2015205); Guangdong Science and Technology Project (2013B090700015); Guangdong Provincial Science and Technology Department Project (2015B020211013)

\section{References}

1 K. Appel, P. Meiser, E. Millán, J. A. Collado, T. Rose, C. C. Gras, R. Carle and E. Muñoz, Fitoterapia, 2015, 105, 73-82.

2 C. M. Bergamini, S. Gambetti, A. Dondi and C. Cervellati, Curr. Pharm. Des., 2004, 10, 1611-1626.

3 W. Liao, Z. Ning, L. Ma, X. Yin, Q. Wei, E. Yuan, J. Yang and J. Ren, Rejuvenation Res., 2014, 17, 422-429.

4 B. Hoesel and J. A. Schmid, Mol. Cancer, 2013, 12, 1.

5 T. T. Zhang, C. L. Lu and J. G. Jiang, J. Funct. Foods, 2015, 18, 423-431.

6 I. Kowalska, D. Jedrejek, L. Ciesla, L. Pecio, M. Masullo, S. Piacente, W. Oleszek and A. Stochmal, J. Agric. Food Chem., 2013, 61, 4417-4423.

7 A. Panusa, A. Zuorro, R. Lavecchia, G. Marrosu and R. Petrucci, J. Agric. Food Chem., 2013, 61, 4162-4168.

8 R. Ilahy, G. Piro, I. Tlili, A. Riahi, R. Sihem, I. Ouerghi, C. Hdider and M. S. Lenucci, Food Funct., 2016, 7, 574-583.

9 K. Ogawa, S. Hirose, S. Nagaoka and E. Yanase, J. Agric. Food Chem., 2016, 64, 204-209. 
10 L. Liu, Y. Sun, T. Laura, X. Liang, H. Ye and X. Zeng, Food Chem., 2009, 112, 35-41.

11 T. Hu, X. W. He, J. G. Jiang and X. L. Xu, Food Funct., 2014, 5, 876-881.

12 T. Hu, X. W. He and J.-G. Jiang, J. Agric. Food Chem., 2014, 62, 8608-8615.

13 J. Zheng, L. Tang, X.-D. Xian, S. X. Zhou, H. M. Shi, Y. Jiang, Y.-Q. Gu, G. Liu and P.-F. Tu, Planta Med., 2009, 75, 14101414.

14 P. Izadiyan and B. Hemmateenejad, Food Chem., 2016, 190, 864-870.

15 G. Picariello, V. De Vito, P. Ferranti, M. Paolucci and M. G. Volpe, J. Food Compos. Anal., 2016, 45, 50-57.

16 E. A. Abourashed, C. L. A. Roberson and N. Elsharkawy, J. Diet. Suppl., 2016, 13, 171-184.

17 T. T. Zhang, C. Y. Zheng, T. Hu, J. G. Jiang, J. W. Zhao and W. Zhu, MedChemComm, 2018, DOI: 10.1039/c7md00477j.

18 T. T. Zhang, X. L. Xu, M. H. Jiang and J. G. Jiang, Food Funct., 2013, 4, 1581-1585.

19 T. T. Zhang, L. Yang and J. G. Jiang, Food Funct., 2015, 6, 2205-2214.

20 T. T. Zhang, M. Wang, L. Yang, J. G. Jiang, J. W. Zhao and W. Zhu, J. Funct. Foods, 2015, 18, 235-243.

21 T. T. Zhang, L. Yang and J. G. Jiang, J. Funct. Foods, 2015, 19, 575-583.

22 K. L. Wolfe and R. H. Liu, J. Agric. Food Chem., 2007, 55, 8896-8907.

23 W. Liao, Z. Ning, L. Chen, Q. Wei, E. Yuan, J. Yang and J. Ren, J. Agric. Food Chem., 2014, 62, 8648-8654.

24 T. T. Zhang, C. L. Lu, J. G. Jiang, M. Wang, D. M. Wang and W. Zhu, Carbohydr. Polym., 2015, 130, 307-315.

25 D. Gunawardena, N. Karunaweera, S. Lee, F. van Der Kooy, D. G. Harman, R. Raju, L. Bennett, E. Gyengesi, N. J. Sucher and G. Münch, Food Funct., 2015, 6, 910-919.

26 S. Hooshmand, A. Kumar, J. Y. Zhang, S. A. Johnson, S. C. Chai and B. H. Arjmandi, Food Funct., 2015, 6, 17191725 .
27 T. T. Zhang, L. Yang and J. G. Jiang, Food Funct., 2015, 6, 2588-2597.

28 A. Filipek, M. E. Czerwińska, A. K. Kiss, M. Wrzosek and M. Naruszewicz, Phytomedicine, 2015, 22, 1255-1261.

29 K. Srisook, E. Srisook, W. Nachaiyo, M. Chan-In, J. Thongbai, K. Wongyoo, S. Chawsuanthong, K. Wannasri, S. Intasuwan and K. Watcharanawee, J. Ethnopharmacol., 2015, 165, 94102.

30 N. M. Elsherbiny, S. Ahmad, M. Naime, A. M. Elsherbini, S. Fulzele, M. M. Al-Gayyar, L. A. Eissa, M. M. El-Shishtawy and G. I. Liou, Life Sci., 2013, 93, 78-88.

31 Y. Chen, G. Chen, X. Fu and R. H. Liu, J. Agric. Food Chem., 2014, 63, 169-176.

32 Y. Chen, G. Wang, H. Wang, C. Cheng, G. Zang, X. Guo and R. H. Liu, PLoS One, 2014, 9, e108140.

33 S. Ahn, M. H. Siddiqi, H. Y. Noh, Y. J. Kim, Y. J. Kim, C. G. Jin and D. C. Yang, Sci. Bull., 2015, 60, 773-784.

34 N. K. Im, Y. S. Jung, J. H. Choi, M. H. Yu and G. S. Jeong, Nat. Prod. Sci., 2014, 20, 51-57.

35 J. Zhen, T. S. Villani, Y. Guo, Y. Qi, K. Chin, M.-H. Pan, C. T. Ho, J. E. Simon and Q. Wu, Food Chem., 2016, 190, 673-680.

36 M. S. Lee, M. S. Kwon, J. W. Choi, T. Shin, H. K. No, J. S. Choi, D. S. Byun, J.-I. Kim and H.-R. Kim, J. Agric. Food Chem., 2012, 60, 9120-9129.

37 B. B. Aggarwal, S. C. Gupta and B. Sung, Br. J. Pharmacol., 2013, 169, 1672-1692.

38 G. Costa, J. P. Ferreira, C. Vitorino, M. E. Pina, J. J. Sousa, I. V. Figueiredo and M. T. Batista, J. Ethnopharmacol., 2016, 178, 222-228.

39 R. Sarkar, R. Roy and A. N. Chaudhuri, Int. J. Curr. Microbiol. Appl. Sci., 2015, 4.

40 Y. Park, S. A. Yoo, W.-u. Kim, C.-S. Cho and C.-H. Yoon, J. Immunol., 2015, 194, 48.22.

41 S. Hirai, S. Horii, Y. Matsuzaki, S. Ono, Y. Shimmura, K. Sato and Y. Egashira, Life Sci., 2014, 117, 1-6. 